\title{
Uso de células-tronco cultivadas ex vivo na reconstrução da superfície ocular
}

\author{
Use of stem cells cultured ex vivo for ocular surface reconstruction
}

José Reinaldo da Silva Ricardo ${ }^{1}$, José Alvaro Pereira Gomes ${ }^{1}$

\section{RESUMO}

Lesões na superfície ocular podem atingir as células-tronco do limbo e causar deficiência límbica. A deficiência límbicaé caracterizada pela conjuntivalização, que pode ser definida como a invasão do epitélio conjuntival sobre a córnea. Este processo é acompanhado por graus variáveis de alterações corneanas, como neovascularização, inflamação, erosões recorrentes, defeitos epiteliais persistentes, destruição da membrana basal do epitélio e cicatrização estromal. Frequentemente, estas alterações estão associadas à diminuição da acuidade visual, fotofobia e desconforto ocular. O melhor tratamento para essa afecção não é conhecido e possibilidades variam em casos uni ou bilaterais. Entre os tratamentos disponíveis, o transplante de limbo autólogo ou alógeno é um dos mais utilizados. Para melhorar os resultados dos transplantes alógenos, alguns pesquisadores utilizam o transplante de epitélio da córnea cultivado em laboratório pela expansão ex vivo de células-tronco epiteliais límbicas. Mas devido à limitada disponibilidade de tecido autólogo do limbo e o risco de complicações associadas à imunossupressão em transplante de tecido alógeno pesquisas de outras opções de células-tronco cultivadas ex vivo têm sido descritas em fase experimental e clínica. Essa revisão descreve os novos tipos de células-tronco cultivadas ex vivo, seus resultados atuais e potencialidades futuras.

Descritores: Células-tronco adultas/transplante; Âmnio; Técnicas de cultura de células/métodos; Células epiteliais/transplante; Ceratoconjuntivite/cirurgia; Limbo da córnea/citologia; Resultado de tratamento

\begin{abstract}
Lesions on the ocular surface can destroy the stem cells from the limbus and cause limbal stem cell deficiency. The limbal stem cell deficiency is marked by conjunctivalization, which can be defined as the invasion of conjunctival epithelium over the cornea. This process is accompanied by varying degrees of corneal changes such as neovascularization, inflammation, recurrenterosions, persistent epithelial defects, destruction of basement membrane of epithelium and stromal healing. Often, these changes are associated with poor visual acuity, photophobia and ocular discomfort. The best treatment for this disease is not known and varies in unilateral or bilateral cases. Among the treatments available, transplantation of limbal autograft or allograft is one of the most used. To improve the outcome of allotransplantation, some researchers use the transplantation of corneal epithelium cultured in the laboratory by ex vivo expansion of limbal stem cells, but due to limited availability of autologous tissue from the limbus and the risk of complications associated with immunosuppression in allogeneic tissue transplantation, researches of others options of stem cell cultured ex vivo have been described in experimental and clinical stage. This review describes the new types of stem cells cultured ex vivo, their current results and future potential.
\end{abstract}

Keywords: Adult stem cells/transplantation; Amnion; Cell culture techniques/ methods; Epithelialcells/transplantation;Keratoconjunctivitis/surgery; Limbus cornea/cytology; Treatment outcome

\section{INTRODUÇÃO}

A s superfícies externas da córnea e da conjuntiva são recobertas por epitélios altamente especializados, que são derivados de células precursoras genotipicamente diversas. Ambos são epitélios do tipo escamoso estratificado não-queratinizado, formados por camadas de células que continuamente se renovam e se regeneram. As camadas basais contêm células-tronco (CTs) semiquiescentes capazes de autoregeneração e também de criar outras células que se diferenciam e migram para a superfície externa, quando cessa a divisão celular ${ }^{(1)}$.

Esses epitélios são separados entre si por uma zona de transição conhecida como limbo. Acredita-se que as paliçadas de Vogt localizadas no limbo contenham estruturas chamadas criptas epiteliais límbicas que representam o nicho das CTs

Trabalho realizado no Centro Avançado de Superfície Ocular (CASO); Setor de Doenças Oculares Externas e Córnea, Departamento de Oftalmologia, Universidade Federal de São Paulo UNIFESP - São Paulo (SP), Brasil.

${ }^{1}$ Médico, Departamento de Oftalmologia da Universidade Federal de São Paulo - UNIFESP - São Paulo (SP), Brasil.

Endereço para correspondência: José Reinaldo da Silva Ricardo. R. Apiacais, 600 Apto. 123 - São Paulo (SP) - CEP 05017-020 - E-mail: reinaldoricardo@bol.com.br

Recebido para publicação em 19.08.2010

Última versão recebida em 14.10.2010

Aprovação em 25.10.2010 epiteliais corneanas (2). Por outro lado, o nicho das CTs da conjuntiva humana está localizado na camada basal das conjuntivas palpebral, bulbar e forniceal, embora com maior concentração de CTs no fórnice superior. Essas CTs da conjuntiva dão origem a dois tipos de células: as células epiteliais da conjuntiva e as células caliciformes ${ }^{(3)}$.

O limbo apresenta características especiais. O epitélio é formado por 10 a 12 camadas de células, a camada de Bowman está ausente e a membrana basal do epitélio fica diretamente em contato com o estroma, formado por fibras colágenas menos organizadas, vasos sanguíneos, nervos, células de Langherans e melanócitos. As CTs do limbo localizam-se na camada basal do epitélio límbico juntamente com células amplificadoras transitórias (TACs) $)^{(4)}$. Além dessas características anatômicas, as CTs sofrem a influência de citocinas, que exercem um controle regulatório ainda pouco conhecido. De acordo com a sua função, as citocinas podem ser divididas em três tipos ${ }^{(5)}$ :

Tipo I: secretadas no epitélio com receptores no estroma (TGF $\alpha, I L-1 \beta, P D G F)$.

Tipo II: secretadas e com receptores no epitélio e estroma (IGF-1,TGF $\beta 1$,TGF $\beta 2$, b-FGF).

Tipo III: secretadas no estroma, enquanto seus receptores são encontrados no epitélio (KGF, HGF).

Segundo Tackács, muitos destes fatores (KGF, HGF, NGF, TGF $\beta 1, T G F \beta 2$, b-FGF) têm sido identificados na membrana amniótica humana, o que pode favorecer o crescimento de células epiteliais in vitro ${ }^{(4)}$. Esse mecanismo molecular exerce 
controle regulatório sobre a diferenciação celular do epitélio da córnea que ocorre com as células migrando em duas direções, uma vertical em direção a superfície do epitélio e a outra horizontal em direção ao centro da córnea.

Nesta população de células limbo-corneanas, o tamanho se correlaciona com a diferenciação celular e a capacidade proliferativa. As CTs são as menores em tamanho, com alta relação núcleo: citoplasma, com maior densidade celular na camada basal, e também apresentam características de ciclo celular lento(4). Devido à ausência de um marcador específico para CTs, procura-se diferenciar globalmente o seu fenótipo por marcadores positivos e negativos (Tabela 1$)^{(6)}$.

\section{DeficiênCia límbica e suas causas}

A integridade da superfície ocular e sua capacidade de autoregeneração dependem da presença de um número adequado de CTs. Diversas afecções podem destruir as CTs do limbo e causar deficiência límbica, parcial ou total ${ }^{(7)}$. Prabhasawat et al., baseados nos seus achados de citologia de impressão, estabeleceram uma classificação da deficiência límbica em duas categorias distintas: 1 - Aplasia ou perda total das célulastronco límbicas devidas à destruição; e 2- Perda gradual das células-tronco límbicas devida ao suporte estromal insuficiente (Figura 1$)^{(7)}$. Os pacientes incluídos na primeira categoria têm história clínica identificável de destruição do limbo e consequente perda das células germinativas límbicas, como por exemplo, nas queimaduras químicas oculares, síndrome de Stevens Johnson, penfigóide ocular cicatricial, múltiplas cirurgias ou crioterapia na região do limbo, ceratopatia induzida por lente de contato, ceratites infecciosas graves e toxicidade induzida por antimetabólitos. Os incluídos na segunda categoria não apresentam história prévia de destruição, mas evoluem com perda gradual da função das células-tronco límbicas, provavelmente devida ao suporte insuficiente do microambiente estromal límbico, como por exemplo, na aniridia, ceratite associada a deficiências endócrinas múltiplas, ceratopatia neurotrófica (neural ou isquêmica), desordens inflamatórias periféricas e limbites crônicas, ceratopatia induzida por irradiação, pterígio e idiopáticas.

\section{Tratamento dA DEFICIÊNCIA LÍMBICA}

O tratamento da deficiência límbica unilateral é o transplante autólogo de limbo (CLAU) ${ }^{(8)}$. Já na deficiência límbica total bilateral, a ausência de tecido límbico autólogo saudável torna necessária a obtenção de uma fonte externa de CTs epiteliais corneanas. Essa fonte pode ser obtida pelo transplante de limbo do anel corneoescleral de olhos viáveis de cadáver (KLAL) ou do limbo e conjuntiva de doador cadáver (c-CLAU) e do transplante alógeno de conjuntiva de doador vivo relacionado (Ir-CLAU) (parentes de primeiro grau) ${ }^{(8)}$.

Outra opção usada no tratamento da deficiência límbica é o transplante de membrana amniótica, associado ou não ao transplante de limbo alógeno (de doador cadáver) ${ }^{(9)}$. Nos casos de deficiência límbica parcial, o transplante de membrana amniótica é suficiente para reconstruir a superfície ocular, sendo, entretanto, necessário associar o transplante de limbo nas deficiências límbicas totais.

Apesar do transplante de limbo alógeno, seja de doador cadáver ou de doador vivo, ter sido um marco no tratamento da deficiência límbica bilateral, torna-se claro que o entusiasmo inicial tem se retraído com a observação de que muitos desses enxertos acabam falindo a longo prazo, o que contrasta com a excelente sobrevida dos enxertos autólogos ${ }^{(10)}$. Como alternativa para os casos bilaterais, novas técnicas de cultivo de CTs vêm sendo desenvolvidas.

\section{BIOENGENHARIA TECIDUAL UTILIZANDO CÉLULAS-TRONCO EXPANDIDAS EX VIVO}

A medicina regenerativa ou terapia celular procura empregar CTs embrionárias ou adultas, direcionando sua diferenciação no sentido de um tecido específico para repor ou reparar tecidos lesados. Com os avanços da bioengenharia de tecidos, tornou-se possível reproduzir o tecido desejado no laboratório para ser transplantado. CTs cultivadas ex vivo do limbo, mucosa oral, conjuntiva e membrana amniótica já foram transplantadas em humanos.

\section{Obtenção de tecido e cultivo em laboratório}

O primeiro passo para o cultivo de células ex vivo é realizar a biópsia. O tamanho da biópsia e o local dependem da técnica empregada e da origem das CTs. A biópsia de limbo varia de 1-3 $\mathrm{mm}^{2} \times 2 \mathrm{~mm}^{2}\left(6 \mathrm{~mm}^{2}\right)$, podendo ser realizada no olho contralateral saudável, de doador HLA compatível ou de cadáver. A biópsia de conjuntiva varia de $2 \mathrm{~mm}^{2} \times 3 \mathrm{~mm}^{2}$, obtida geralmente do fórnice superior. No caso da biópsia de mucosa oral, o tamanho varia de 2-3 $\times 9 \mathrm{~mm}^{2(11)}$. Essas biópsias

Tabela 1. Resumo da distribuição dos marcadores das células-tronco epiteliais na córnea e no limbo

\begin{tabular}{|c|c|c|c|c|}
\hline \multirow[b]{2}{*}{ Marcadores } & \multicolumn{2}{|c|}{ Limbo } & \multicolumn{2}{|c|}{ Córnea } \\
\hline & Basal & Suprabasal & Basal & Suprabasal \\
\hline P63 & +++ & \pm & - & - \\
\hline$A B C G-2$ & +++ & \pm & - & - \\
\hline Integrina $\alpha 9$ & +++ & \pm & - & - \\
\hline Integrina $\beta 1$ & +++ & + & +++ & ++ \\
\hline EGFR & +++ & + & +++ & ++ \\
\hline A-enolase - & +++ & + & ++ & + \\
\hline Integrina $\alpha 6$ & +++ & + & ++ & + \\
\hline Nestina & - & +++ & + & +++ \\
\hline E-caderina & - & +++ & + & +++ \\
\hline Conexina 43 & - & +++ & + & +++ \\
\hline K3 & & +++ & +++ & +++ \\
\hline K19 & +++ & + & +++ & +++ \\
\hline
\end{tabular}

Fonte: Chen $^{6}$ 

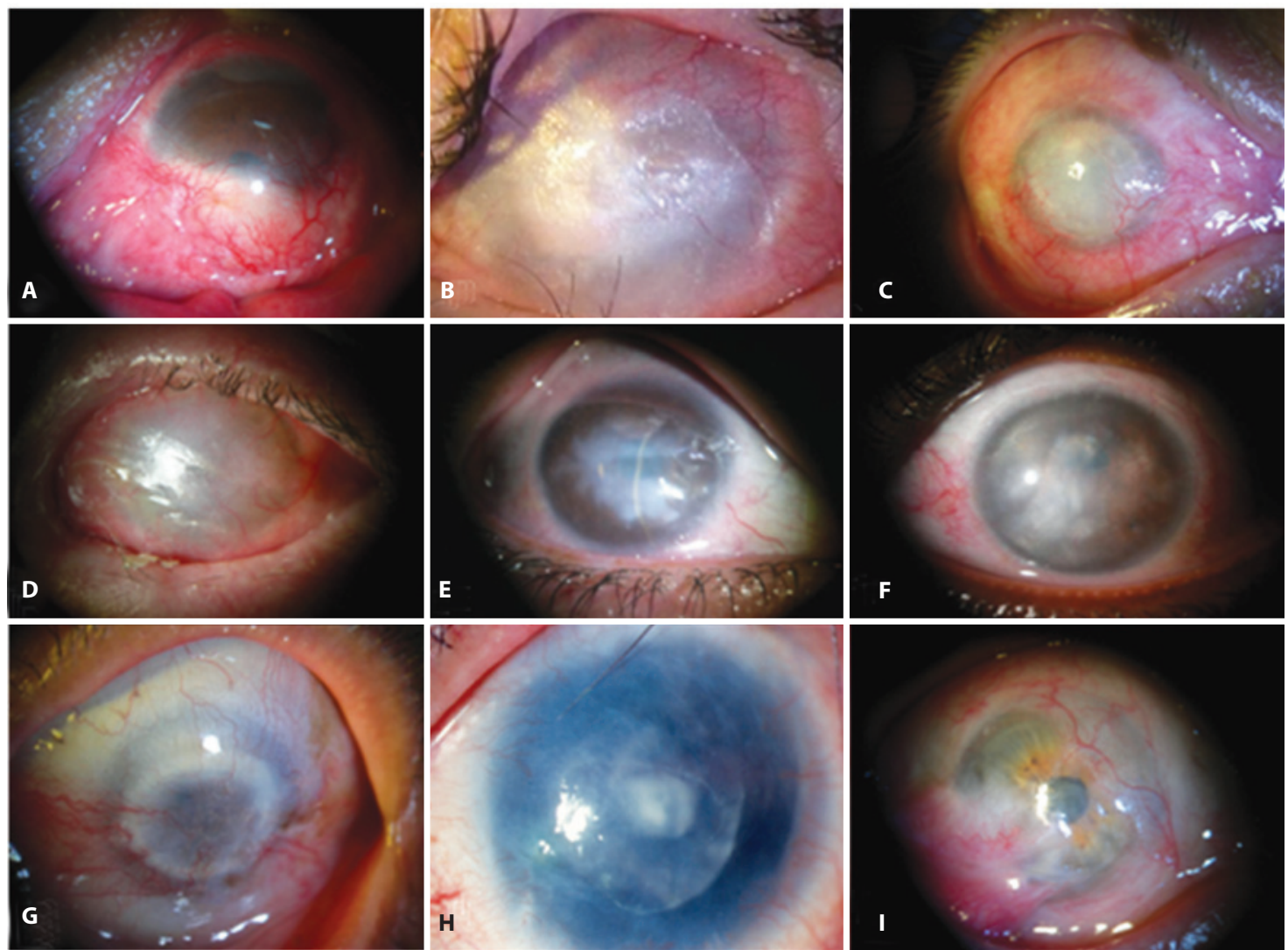

Figura 1. Pacientes com deficiência límbica secundária a aplasia ou destruição das células-tronco límbicas: queimadura química (A), síndrome de Stevens-Johnson (B), múltiplas cirurgias (C), e penfigóide ocular cicatricial (D). Deficiência límbica secundária a perda gradual das células-tronco límbicas devido ao suporte estromal insuficiente: síndrome poliglandular autoimune (E), estafilococcia (F), idiopática (G), aniridia (H) e pterígio (I).

podem ser cultivadas ex vivo de duas formas: sistema de cultura em explante e suas variações, e sistema de cultura em suspensão (Figura 2)(11).

O sistema de cultura em explante utiliza a membrana amniótica, que atua como um substrato e carreador para as células cultivadas (Figura 3). A membrana amniótica pode ser epitelizada ou desepitelizada através de várias técnicas como a digestão enzimática, tratamento químico ou mecânico. Há controvérsias em relação a utilizar membrana amniótica com ou sem seu epitélio na expansão ex vivo das CTs do epitélio corneano para reconstrução da superfície ocular. Alguns trabaIhos mostram os benefícios da membrana intacta, pois mantém as células em um estado indiferenciado, com um maior potencial de CTs, porém com limitada formação de estruturas de adesão, o que pode comprometer a viabilidade das células transplantadas. Por outro lado, outros autores observaram melhores resultados com a membrana desepitelizada, com formação de epitélio mais confluente e com maior número de estruturas de adesão, o que aumenta a segurança do procedimento ${ }^{(12)}$

A composição do meio de cultura é muito importante no cultivo celular. Os meios de cultura contêm nutrientes e mitógenos que estimulam as CTs epiteliais a proliferarem e migrarem do explante para cobrir a superfície da membrana amniótica, o que ocorre entre 14-28 dias (Tabela 2). Soro fetal bovino ou outros produtos de origem animal são usados em todos os estudos. Para reduzir os riscos de transmissão de vírus e príons, alguns autores substituíram o soro bovino por soro autólogo do paciente com sucesso ${ }^{(11)}$. Um processo adicional chamado "air-lifting" é usado por alguns pesquisadores. Este processo requer que o nível do meio de cultura seja baixado ao nível da superfície do epitélio. Isto promove a estratificação e diferenciação do epitélio(11).

O sistema de cultura com explante e fibroblastos $3 T 3$ de camundongos é uma variação da técnica de cultura em explante ${ }^{(13)}$. Ela usa uma camada adicional de fibroblastos 3T3 isolados de embriões de camundongos. Tanto a membrana amniótica quanto os fibroblastos 3 T3 inibem a diferenciação das células corneanas in vitro, o que permitem a expansão da população de $\mathrm{CTs} s^{(11)}$.

O sistema de cultura em suspensão utiliza a enzima dispase para digerir o colágeno da membrana basal com consequente liberação das células epiteliais do estroma da biópsia colhida e a tripsina para separar as células epiteliais límbicas entre si. A suspensão de células é então colocada sobre um substrato que pode ser a membrana amniótica ou disco de cultura com fibroblastos 3T3 de camundongos em meio de cultura específico. Quando a confluência é atingida, as células são transferidas para superfície ocular através de carreadores como a membrana amniótica, lentes de contato, gaze de parafina, campo de colágeno ou gel de fibrina ${ }^{(11)}$.

A evidência da presença de CTs é baseada nas seguintes características: habilidade das células formarem colônias em meio de cultura (somente CTs possuem essa habilidade); análise imuno-histológica do tecido mostrando a formação de um epitélio bem formado, com estruturas típicas e expressando marcadores de epitélio; e regeneração do epitélio corneano e sobrevida a longo prazo em olhos com deficiência límbica total. 


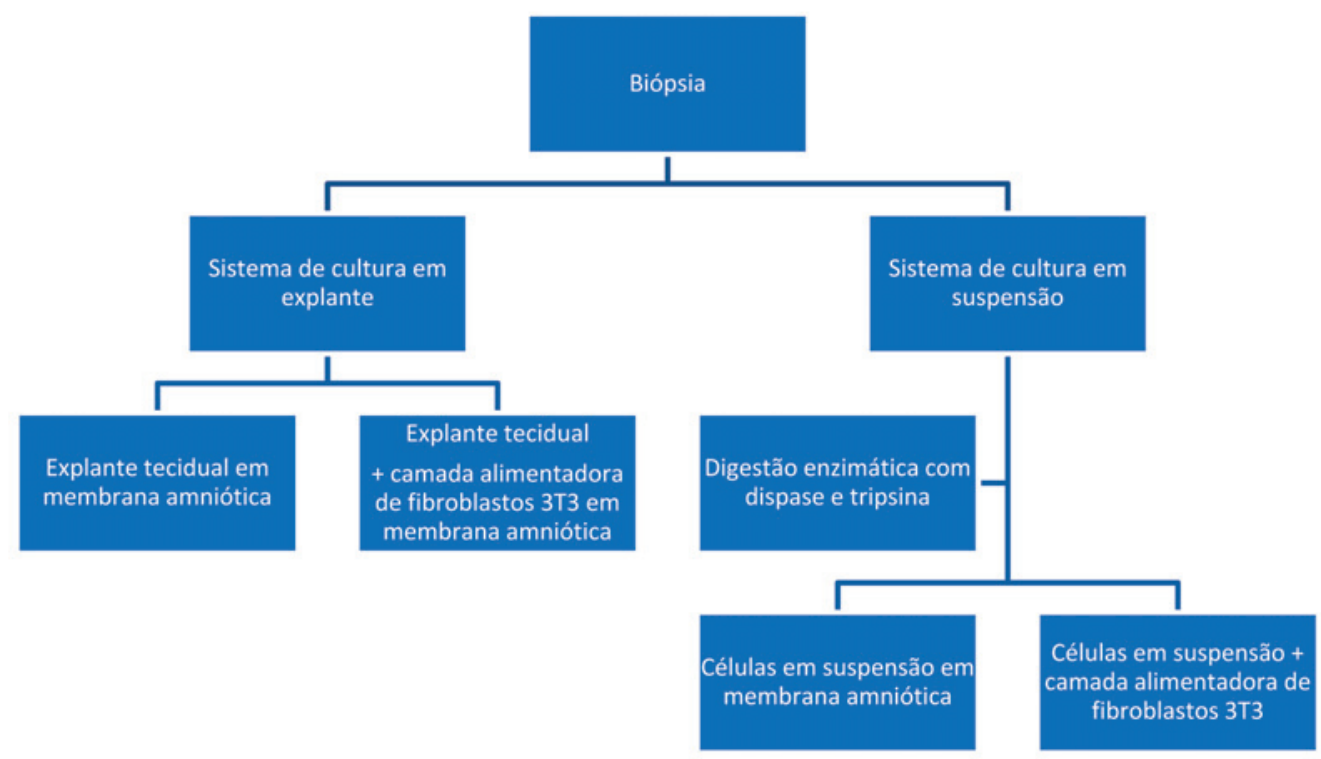

Figura 2. Após a realização da biópsia, o explante tecidual pode ser cultivado em dois sistemas de cultura. No sistema de cultura em explante, o explante tecidual é cultivado sobre membrana amniótica e meio de cultura com ou sem uma camada alimentadora de fibroblastos 3T3. No sistema de cultura em suspensão, o explante tecidual é submetido à digestão enzimática de dispase e tripsina. As células em suspensão podem ser cultivadas sobre membrana amniótica ou placa de cultura com adição de camada alimentadora de fibroblastos 3 T3.
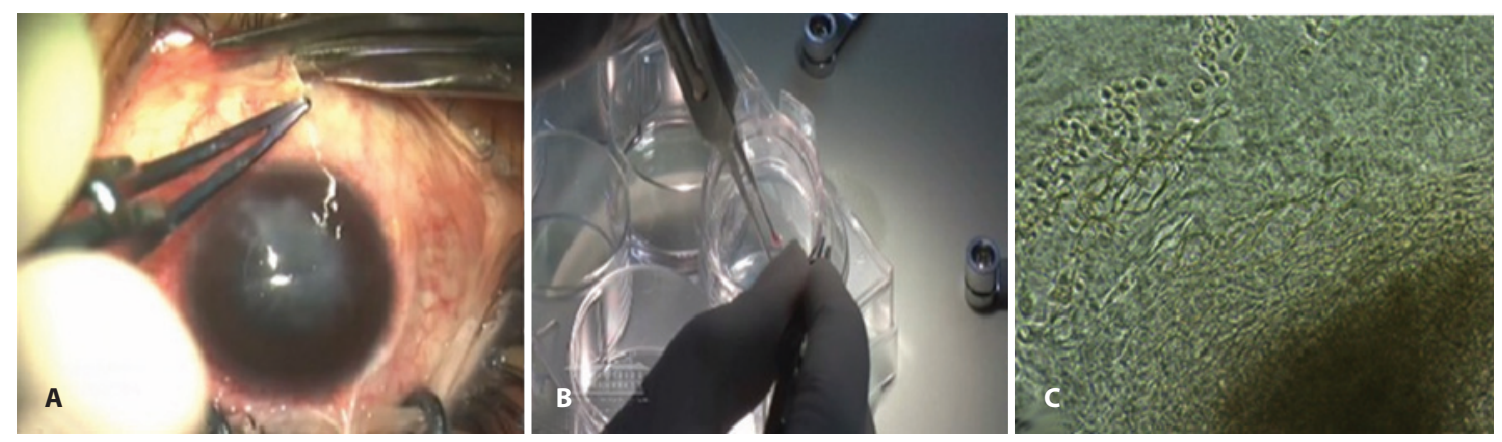

Figura 3. Exemplo de cultivo de células-tronco da conjuntiva expandidas em laboratório. Biópsia realizada no fórnice superior (A). Explante tecidual sendo colocado sobre membrana amniótica desepitelizada presa ao insert de cultura e meio de cultura DMEN: F12 (B). A expansão das células epiteliais sobre a membrana amniótica é observada no microscópio de contraste de fase invertido (C).

\section{TRANSPLANTE DE CÉLULAS-TRONCO EPITELIAIS LÍMBICAS EXPANDIDAS EX VIVO}

Pellegrini et al. foram os primeiros a publicarem os resultados da expansão ex vivo de suspensão de CTs epiteliais do limbo no tratamento da deficiência límbica em humanos ${ }^{(14)}$. Posteriormente, vários autores ${ }^{(14-24)}$ publicaram trabalhos com bons resultados (Tabela 3 ).

Esta técnica tem vantagens teóricas sobre o tratamento convencional. Em relação à CLAU e Ir-CLAU, a biópsia límbica requerida é substancialmente menor. Isto minimiza o risco de indução de deficiência límbica no olho doador e ainda mantém o limbo viável para que uma nova biópsia possa ser realizada futuramente. Outra vantagem sobre KLAL e Ir-CLAU é reduzir o risco de rejeição devido à ausência de células de Langerhans apresentadoras de antígeno nas células cultivadas ex vivo. Contudo, no caso de deficiência límbica bilateral, a alternativa é usar uma fonte alógena de células límbicas, com necessidade de imunossupressão sistêmica, ou usar outra fonte autóloga de células epiteliais.
Segundo Shortt et al., quando analisados os resultados dos trabalhos com dados suficientes para interpretar os critérios de sucesso do transplante de células do limbo cultivadas ex vivo para o tratamento de deficiência límbica, uma melhora dos parâmetros clínicos foi encontrada em 131 (77\%) de 170 olhos (variação de 33-100\%)(11). Alguns autores demonstraram que o padrão imunocitoquímico e histopatológico dos epitélios cultivados ex vivo transplantados eram compatíveis com o fenótipo corneano(11).

\section{TRANSPLANTE DE CÉLULAS-TRONCO EPITELIAIS DA MUCOSA ORAL EXPANDIDAS EX VIVO}

Vários pesquisadores publicaram os resultados da reconstrução da córnea na deficiência límbica bilateral total utilizando tecido da mucosa oral autóloga cultivada ex vivo (Tabela 4)(25-28) A taxa de sucesso relatada foi de 67 a 100\%. Uma vantagem do uso dessas CTs é poder prescindir da imunossupressão. No entanto, alguns problemas com essa técnica ainda persistem. A taxa de neovascularização corneana periférica, que pode 
interferir nos resultados de possíveis transplantes, é muito alta, mas sem progressão para conjuntivalização e diminuição da acuidade visual. Em certas doenças autoimunes, como o penfigóide ocular cicatricial, a mucosa oral pode teoricamente secretar um antígeno de membrana basal, fazendo essa fonte de tecido menos desejável neste grupo de pacientes. Por último, o uso de tecido de origem ocular é sempre preferível sobre tecido de origem não-ocular ${ }^{(11)}$.

\section{Transplante de CÉLULAS-TRONCO EPITELIAIS DA CONJUNTIVA EXPANDIDAS EX VIVO}

Em 1999, Pellegrini et al. conseguiram identificar CTs conjuntivais uniformemente distribuídas na conjuntiva bulbar e dos fórnices ${ }^{(3)}$. Esses autores também evidenciaram a presença de células caliciformes em culturas de células amplificadoras transitórias, sugerindo uma origem comum à das células epiteliais conjuntivais, porém com diferenciação mais tardia. Como o transplante de células conjuntivais teve sucesso em reconstruir algumas doenças da superfície ocular ${ }^{(29)}$, Ang et al. testaram em modelos de coelhos com deficiência límbica a possibilidade de utilizar a cultura de epitélio conjuntival humano

\begin{tabular}{lc} 
Tabela 2. Componentes básicos e suplementos de \\
meio de cultivo de células epiteliais \\
\hline Componentes (unidade) & Concentração \\
\hline DMEM:Ham's F12 & $1: 1$ \\
Soro bovino fetal (\%) & $5-10$ \\
Soro autólogo do paciente (\%) & 10 \\
EGF (ng/ml) & $5-10$ \\
Insulina (ng/ml) & $2,5-5$ \\
Transferrina ( $\mu \mathrm{g} / \mathrm{ml})$ & 5 \\
Selenito de sódio $(\mathrm{ng} / \mathrm{ml})$ & 5 \\
Hidrocortisona $(\mu \mathrm{g} / \mathrm{ml})$ & $0,1-0,5$ \\
Toxina colérica subunidade A (ng/ml) & $30-100$ \\
DMSO (\%) & 0,5 \\
Triiodotironina (nmol/ml) & 2 \\
Penicilina/estreptomicina (IU/ml) & 10 \\
Gentamicina ( $\mu \mathrm{g} / \mathrm{ml})$ & 50 \\
Anfotericina B ( $\mu \mathrm{g} / \mathrm{ml})$ & 1,25 \\
\hline
\end{tabular}

como alternativa ao transplante de epitélio corneano ${ }^{(30)}$. Eles mostraram que o transplante de células epiteliais da conjuntiva cultivadas ex vivo tinham resultados clínicos equivalentes ao transplante de células epiteliais límbicas cultivadas ex vivo. (Figura 4).

\section{Transplante DE CÉLULAS-TRONCO EPITELIAIS DA MEMBRANA AMNIÓTICA HUMANA EXPANDIDAS EX VIVO}

Parmar et al. ${ }^{(31)}$ publicaram os resultados do transplante de células epiteliais da membrana amniótica humana na reconstrução da superfície ocular de 3 pacientes com defeito epitelial persistente secundário a queimadura química (1) e ceratopatia neurotrófica (2). Eles conseguiram restaurar o epitélio corneano em todos os casos.

\section{Transplante de CÉlULAS-TRONCO DA POLPA dO DENTE DE LEITE (CTPD)}

As CTPD expressam positividade para marcadores de CTS mesenquimais e, no seu estado indiferenciado, expressam um grupo de marcadores de superfície celular embrionários ${ }^{(32)}$. Devido ao enorme potencial de diferenciação epitelial das CTPD resolvemos testar essas CTs na deficiência límbica. Numa primeira fase, obteve-se a diferenciação das CTPD em células epiteliais com características de CTs epiteliais límbicas. Estudos ultraestruturais, imuno-histoquímicos e moleculares demonstraram que estas células, quando cultivadas em meio de cultura apropriada, apresentam morfologia e expressão antigênica epitelial progenitora (positividade para citoqueratina 3, 18, p63, conexina 43 e ABCG2) ${ }^{(33)}$. Numa segunda fase, após o transplante em olhos de coelhos com deficiência límbica, as córneas foram avaliadas por microscopia óptica e eletrônica e por imunofluorescência com uso de microscopia confocal para caracterização celular. Os achados comprovaram que as CTPD transplantadas foram incorporadas na superfície corneana e diferenciaram-se em células com fenótipo epitelial que expressavam antígeno das CTPD humanas e antígenos epiteliais (citoqueratina 3, 18, p63 e beta-1)(34). Atualmente está em andamento protocolo para o uso dessas CTs em pacientes com deficiência límbica total.

\section{TRANSPLANTE DE CÉlULAS-TRONCO DE OUTRAS LINHAGENS}

Células-tronco de outras origens também podem servir como fonte autóloga no tratamento de doenças da superfície ocular. Além da mucosa oral, conjuntiva e dente de leite,

Tabela 3. Estudos que utilizaram transplante de células epiteliais límbicas cultivadas ex vivo no tratamento de deficiência límbica em humanos

\begin{tabular}{|c|c|c|c|c|c|c|}
\hline Autor/ano & $\begin{array}{c}\text { Número de olhos/ } \\
\text { pacientes }\end{array}$ & $\begin{array}{c}\text { Origem } \\
\text { do tecido }\end{array}$ & Imunossupressor & Etiologia & Taxa de sucesso & $\begin{array}{l}\text { Seguimento } \\
\text { (meses) }\end{array}$ \\
\hline Pellegrini'14 1997 & $2 / 2$ & Auto & Não & Queimadura & 2/2 (100\%) & 24 \\
\hline Schwab' 1999 & $19 / 18$ & Auto/Alo & Não & Múltiplas & $12 / 19(63 \%)$ & $10(2-24)$ \\
\hline Tsai $^{16} 2000$ & $6 / 6$ & Auto & Não & Múltiplas & $6 / 6(100 \%)$ & $15(12-18)$ \\
\hline Rama $^{17} 2001$ & $18 / 18$ & Auto & Não & Queimadura & $14 / 18(78 \%)$ & $17,5(12-27)$ \\
\hline Kolzumi ${ }^{18} 2001$ & $13 / 11$ & Alo & $\operatorname{Sim}$ & Múltiplas & $12 / 13(92 \%)$ & $11,2(9-13)$ \\
\hline Daya $^{19} 2005$ & $10 / 10$ & Alo & $\operatorname{Sim}$ & Múltiplas & $7 / 10(70 \%)$ & $28(12-50)$ \\
\hline Sangwan 202006 & $88 / 86$ & Auto & Não & Múltiplas & $57 / 78(73,1 \%)$ & $29,5(25-34)$ \\
\hline Nakamura 212006 & $9 / 9$ & Auto/Alo & $\operatorname{Sim}$ & Múltiplas & $9 / 9(100 \%)$ & $18,3(3-40,5)$ \\
\hline Shortt 222008 & $10 / 10$ & Auto/Alo & Sim & Múltiplas & $7 / 10(70 \%)$ & $8,7(6-13)$ \\
\hline Gomes $^{23} 2009$ & $1 / 1$ & Alo & $\operatorname{sim}$ & Idiopática & $1 / 1(100 \%)$ & 12 \\
\hline Rama $^{24} 2010$ & $113 / 112$ & Auto & Não & Queimadura & $76,6 \%$ & 120 \\
\hline
\end{tabular}

Auto= autólogo; $\mathrm{Alo}=$ alógeno 
Tabela 4. Estudos que utilizaram transplante de células epiteliais da mucosa oral cultivadas ex vivo no tratamento de deficiência límbica em humanos

\begin{tabular}{|c|c|c|c|c|c|c|}
\hline Autor/ano & Número de olhos/pacientes & Origem & Imunossupressor & Etiologia & Taxa de sucesso & Seguimento (meses) \\
\hline Nishida $^{25} 2004$ & $4 / 4$ & Auto & Não & M & $4 / 4(100 \%)$ & $14(13-15)$ \\
\hline Nakamura 262004 & $6 / 4$ & Auto & Não & M & $6 / 6(100 \%)$ & 13.8 \\
\hline Inatomi ${ }^{27} 2006$ & $15 / 12$ & Auto & Não & M & $10 / 15(67 \%)$ & 20 \\
\hline Ang $^{28} 2006$ & $10 / 10$ & Auto & Não & M & $10 / 10(100 \%)$ & 12.6 \\
\hline
\end{tabular}

Auto= autólogo; $M=$ múltiplas etiologias
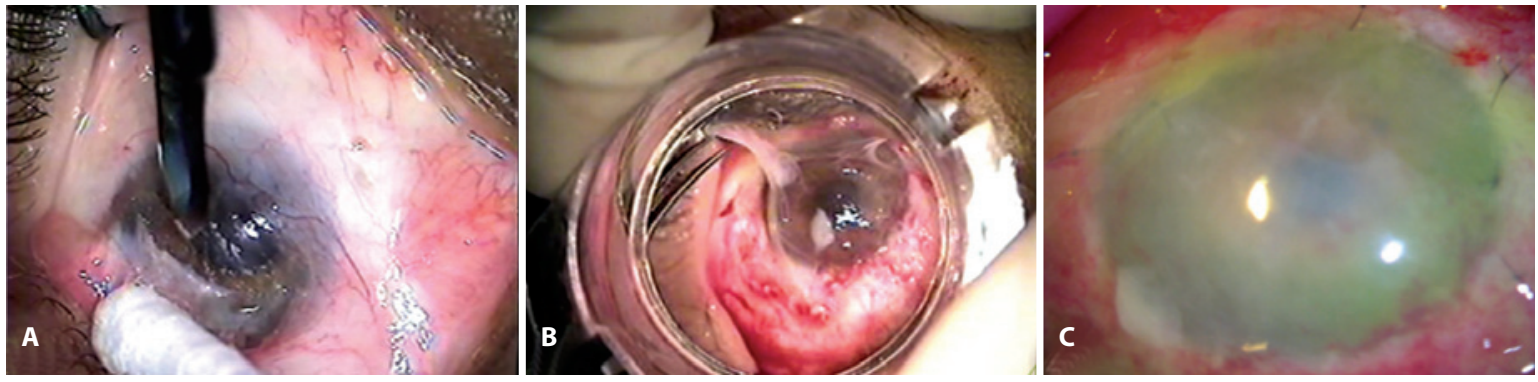

Figura 4. Após o cultivo das células-tronco epiteliais da conjuntiva em laboratório, o paciente com deficiência límbica é submetido à ceratectomia superficial (A). As células-tronco expandidas sobre a membrana amniótica são transferidas para a superfície corneana preparada (B). A membrana amniótica cultivada é recoberta com uma membrana amniótica com função protetora e suturada com nylon 10-0 (C).

alguns estudos vêm utilizando outras fontes como as células mesenquimais da medula óssea ${ }^{(35)}$, a epiderme ${ }^{(36)}$ e o folículo piloso ${ }^{(37)}$. Blazejewska et al.(37) relataram a transdiferenciação das células-tronco do folículo piloso em células corneanas in vitro. Eles observaram padrão imunocitoquímico e morfologia celular compatível com células corneanas.

\section{CONSIDERAÇÕES FINAIS}

Mesmo com um grande número de estudos experimentais na reconstrução da superfície ocular por vários grupos, algumas questões ainda precisam ser respondidas.

A quantidade de CTs presentes na cultura de células ex vivo ainda não foi determinada

O comportamento dessas células transplantadas no paciente ainda não é conhecido. Mesmo com trabalhos mostrando a restauração do epitélio corneano após o tratamento de córneas com deficiência límbica total, isto não é uma evidência direta que CTs do limbo transplantadas tenham sobrevivido. De fato, Daya et al. ${ }^{(19)}$ demonstraram por análise de PCR, que olhos que receberam CTs epiteliais do limbo de doadores não apresentavam mais o DNA do doador entre 7 a 9 meses após o transplante, mas que o epitélio era reposto pelas células do hospedeiro. A renovação do epitélio corneano, provavelmente, é mantida a longo prazo, pela ativação de CTs do limbo residuais latentes que podem ser estimuladas a se multiplicarem após transplante de células límbicas ex vivo. Como alternativa, o epitélio transplantado de alguma forma pode fornecer estímulos quimiotáticos para células progenitoras circulantes na corrente sanguínea ou diretamente a partir da medula óssea para preencher a superfície ocular com mais células.

Estudos recentes mostram que existem células oligopotentes localizadas na região central da córnea ${ }^{(38-39)}$. Essas células podem ser responsáveis pela manutenção do epitélio corneano a curto e médio prazo nos casos que não tenham lesão deste epitélio. No caso de lesão, a capacidade de regeneração dessas células é superada, sendo necessária a existência de CTs do limbo para renovar o epitélio. Esse conceito é importante no transplante de células epiteliais cultivadas ex vivo, porque o tipo de CTs transplantadas, oligopotente ou pluripotente, pode determinar a sobrevida das células transplantadas a longo prazo.

Os componentes estruturais e funcionais do nicho das CTs do limbo ainda não são totalmente conhecidos. A descoberta de fatores-chaves deste nicho que controlam o comportamento das CTs do limbo pode permitir a aplicação nos meios de cultura ex vivo e tornar o cultivo dessas CTs mais eficientes. Infelizmente, ainda não existem marcadores moleculares definitivos para identificar as CTs. O P63 e o ABCG2 são, no momento, os candidatos líderes para essa função.

Um maior tempo de seguimento, padronização dos critérios de sucesso utilizados nos trabalhos, desenvolvimento de um método que detecte essas células transplantadas, definição de quais as melhores indicações para essa técnica, qual a melhor fonte de CTs autólogas para serem transplantadas nos casos bilaterais, ainda precisam ser definidos.

É preciso comparar os resultados do transplante de células epiteliais cultivadas ex vivo com ceratopróteses tipo I e II, que vêm apresentando avanços no tratamento de pacientes com deficiência de células-tronco do limbo ${ }^{(40)}$.

Apesar dessas incertezas, os trabalhos vêm demonstrando excelentes resultados no uso das células-tronco cultivadas exvivo na reconstrução da superfície ocular. Até o momento, essa técnica é empregada em caráter experimental, mas diante dos resultados obtidos, esse procedimento tem um enorme potencial para se tornar a opção de escolha no tratamento de pacientes com doenças da superfície ocular, principalmente nos casos de deficiência límbica total.

\section{REFERÊNCIAS}

1. Revoltella RP, Papini S, Rosellini A, Michelini M. Epithelial stem cells of the eye surface. Cell Prolif. 2007:40(4):445-61.

2. Dua HS, Shanmuganathan VA, Powell-Richards AO, Tighe PJ, Joseph A. Limbal epithelial crypts: a novel anatomical structure and a putative limbal stem cell niche. Br J Ophthalmol. 2005;89(5):529-32 
3. Pellegrini G, Golisano O, Paterna P, Lambiase A, Bonini S, Rama P, De Luca M. Location and clonal analysis of stem cells and their differentiated progeny in the human ocular surface. J Cell Biol. 1999;145(4):769-82

4. Takács L, Tóth E, Berta A, Vereb G. Stem cells of the adult cornea: from cytometric markers to therapeutic applications. Cytometry A. 2009:75(1):54-66

5. Li DQ, Tseng SC. Three patterns of cytokine expression potentially involved in epithelial fibroblast interactions of human ocular surface. J Cell Physiol. 1995; 163(1):61-79.

6. Chen Z, de Paiva CS, Luo L, Kretzer FL, Pflugfelder SC, Li DQ. Characterization of putative stem cell phenotype in human limbal epithelia. Stem Cells. 2004:22(3):355-66.

7. Prabhasawat $P$, Barton K, Burkett G, Tseng SC. Comparison of conjunctival autografts, amniotic membrane grafts, and primary closure of pterygium excision. Ophthalmology. 1997:104(6):974-85

8. Dua HS, Miri A, Said DG. Contemporary limbal stem cell transplantation - a review. Clin Experiment Ophthalmol. 2010;38(2):104-17. Review.

9. Tseng SC, Prabhasawat P, Barton K, Gray T, Meller D. Amniotic membrane transplantation with or without limbal allografts for corneal surface reconstruction in patients with limbal stem cell deficiency. Arch Ophthalmol. 1998;116(4):431-41.

10. Santos MS, Gomes JA, Hofling-Lima AL, Rizzo LV, Romano AC, Belfort R Jr. Surviva analysis of conjunctival limbal grafts and amniotic membrane transplantation in eyes with total limbal stem cell deficiency. Am J Ophthalmol. 2005:140(2):223-30.

11. Shortt AJ, Secker GA, Notara MD, Limb GA, Khaw PT, Tuft SJ, Daniels JT. Transplantation of ex vivo cultured limbal epithelial stem cells: a review of techniques and clinical results. Surv Ophthalmol. 2007:52(5):483-502. Review.

12. Koizumi N, Rigby H, Fullwood NJ, Kawasaki S, Tanioka H, Koizumi K, et al. Comparison of intact and denuded amniotic membrane as a substrate for cell-suspension culture of human limbal epithelial cells. Graefes Arch Clin Exp Ophthalmol. 2007; 245(1):123-34.

13. Cristovam PC, Glória MA, Melo GB, Gomes JAP. Importância do co-cultivo com fibroblastos de camundongo 3T3 para estabelecer cultura de suspensão de células epiteliais do limbo humano. Arq Bras Oftalmol. 2008;71(5):689-94.

14. Pellegrini G, Traverso CE, Franzi AT, Zingirian M, Cancceda R, De Luca M. Long-term restoration of damaged corneal surfaces with autologous cultivated corneal epithelium Lancet. 1997:349(9057):990-3. Comment in: Lancet. 1997:349(9064):1556

15. Schwab IR. Cultured corneal epithelia for ocular surface disease. Trans Am Ophthalmol Soc. 1999;97:891-986

16. Tsai RJ, Li LM, Chen JK. Reconstruction of damaged corneas by transplantation of autologous limbal epithelial cells. N Engl J Med. 2000;343(2):86-93.

17. Rama P, Bonini S, Lambiase A, Golisano O, Paterna P, De Luca M, Pellegrini G. Autologous fibrin-cultured limbal stem cells permanently restore the cornea surface of patients with total limbal stem cell deficiency. Transplantation. 2001;72(9): 1478-85.

18. Koizume N, Inatomi T, Suzuki T, Sotozono C, Kinoshita S. Cultivated corneal epithelial stem cell transplantation in ocular surface disorders. Ophthalmology. 2001;108(9):1569-74

19. Daya SM, Watson A, Sharpe JR, Giledi O, Rowe A, Martin R, James SE. Outcomes and DNA analysis of ex vivo expanded stem cell allograft for ocular surface reconstruction. Ophthalmology. 2005:112(3):470-7.

20. Sangwan VS, Matalia HP, Vemuganti GK, Ifthekar G, Fatima A, Singh S, Rao GN. Early results of penetrating keratoplasty after cultivated limbal epithelium transplantation. Arch Ophthalmol. 2005;123(3):334-40. Erratum in: Arch Ophthalmol. 2006; 124(10):1483

21. Nakamura T, Inatomi T, Sotozono C, Ang LP, Koizumi N, Yokoi N, Kinoshita S. Transplantation of autologous serum-derived cultivated corneal epithelial equivalents for the treatment of severe ocular surface disease. Ophthalmology. 2006; 113(10):1765-72.

22. Shortt AJ, Secker GA, Rajan MS, Meligonis G, Dart JK, Tuft SJ, Daniels JT. Ex vivo expansion and transplantation of limbal epithelial stem cells. Ophthalmology. 2008:115(11):1989-97.

23. Gomes JAP, Pazos HSB, Silva ABE, Cristovam PC, Belfort Júnior R. Transplante de células-tronco epiteliais límbicas alógenas expandidas ex vivo sobre membrana amniótica: relato de caso. Arq Bras Oftalmol. 2009:72(2):254-6.

24. Rama P, Matuska S, Paganoni G, Spinelli A, De Luca M, Pellegrini G. Limbal stemcell therapy and long-term corneal regeneration. N Engl J Med 2010;363(2):147-55.

25. Nishida K, Yamato M, Hayashida Y, Watanabe K, Yamamoto K, Adachi E, et al. Corneal reconstruction with tissue-engineered cell sheets composed of autologous oral mucosal epithelium. N Engl J Med. 2004;351(12):1187-96. Comment in: N Engl J Med. 2004;351(12):1170-2

26. Nakamura T, Inatomi T, Sotozono C, Amemiya T, Kanamura N, Kinoshita S. Transplantation of cultivated autologous oral mucosal epithelial cells in patients with severe ocular surface disorders. Br J Ophthalmol. 2004;88(10):1280-4.

27. Inatomi T, Nakamura T, Kojyo M, Koizumi N, Sotozono C, Kinoshita S. Ocular surface reconstruction with combination of cultivated autologous oral mucosal epithelial transplantation and penetrating keratoplasty. Am J Ophthalmol. 2006;142(5):757-64.

28. Ang LP, Nakamura T, Inatomi T, Sotozono C, Koizumi N, Yokoi N, Kinoshita S. Autologous serum-derived cultivated oral epithelial transplants for severe ocular surface disease. Arch Ophthalmol. 2006;124(11):1543-51.

29. Tan DT, Ang LP, Beuerman RW. Reconstruction of the ocular surface by transplantation of a serum-free derived cultivated conjunctival epithelial equivalent. Transplantation. 2004:77(11):1729-34.

30. Ang LP, Tanioka H, Kawasaki S, Ang LP, Yamasaki K, Do TP, et al. Cultivated human conjunctival epithelial transplantation for total limbal stem cell deficiency. Invest Ophthalmol Vis Sci. 2010:51(2):758-64.

31. Parmar DN, Alizadeh H, Awwad ST, Li H, Neelam S, Bowman RW, et al. Ocular surface restoration using non-surgical transplantation of tissue-cultured human amniotic epithelial cells. Am J Ophthalmol. 2006:141(2):299-307.

32. Kerkis I, Kerkis A, Dozortsev D, Stukart-Parsons GC, Gomes Massironi SM, Pereira LV, et al. Isolation and characterization of a population of immature dental pulp stem cells expressing OCT-4 and other embryonic stem cell markers. Cells Tissues Organs. 2006;184(3-4):105-16

33. Monteiro BG, Serafim RC, Melo GB, Silva MC, Lizier NF, Maranduba CM, et al. Human immature dental pulp stem cells share key characteristic features with limbal stem cells. Cell Prolif. 2009;42(5):587-94.

34. Gomes JA, Geraldes Monteiro B, Melo GB, Smith RL, Cavenaghi Pereira da Silva M, Lizier NF, et al. Corneal reconstruction with tissue-engineered cell sheets composed of human immature dental pulp stem cells. Invest Ophthalmol Vis Sci. 2010; 51(3):1408-14

35. Ma Y, Xu Y, Xiao Z, Yang W, Zhang C, Song E, et al. Reconstruction of chemically burned rat corneal surface by bone marrow-derived human mesenchymal stem cells. Stem Cells. 2006;24(2):315-21

36. Yang X, Moldovan NI, Zhao Q, Mi S, Zhou Z, Chen D, et al. Reconstruction of damaged cornea by autologous transplantation of epidermal adult stem cells. Mol Vis. 2008; 14:1064-70

37. Blazejewska EA, Schlötzer-Schrehardt U, Zenkel M, Bachmann B, Chankiewitz E, Jacobi C, Kruse FE Corneal limbal microenvironment can induce transdifferentiation of hair follicle stem cells into corneal epithelial-like cells. Stem Cells. 2009;27(3): $642-52$

38. Majo F, Rochat A, Nicolas M, Jaoudé GA, Barrandon Y. Oligopotent stem cells are distributed throughout the mammalian ocular surface. Nature. 2008;456(7219): 250-4. Comment in: Nature. 2010;463(7284):E10-1; discussion E11.

39. Dua HS, Miri A, AlomarT, Yeung AM, Said DG. The role of limbal stem cells in corneal epithelial maintenance: testing the dogma. Ophthalmology. 2009;116(5):856-63.

40. Sayegh RR, Ang LP, Foster CS, Dohlman CH. The Boston keratoprosthesis in StevensJohnson syndrome. Am J Ophthalmol. 2008;145(3):438-44

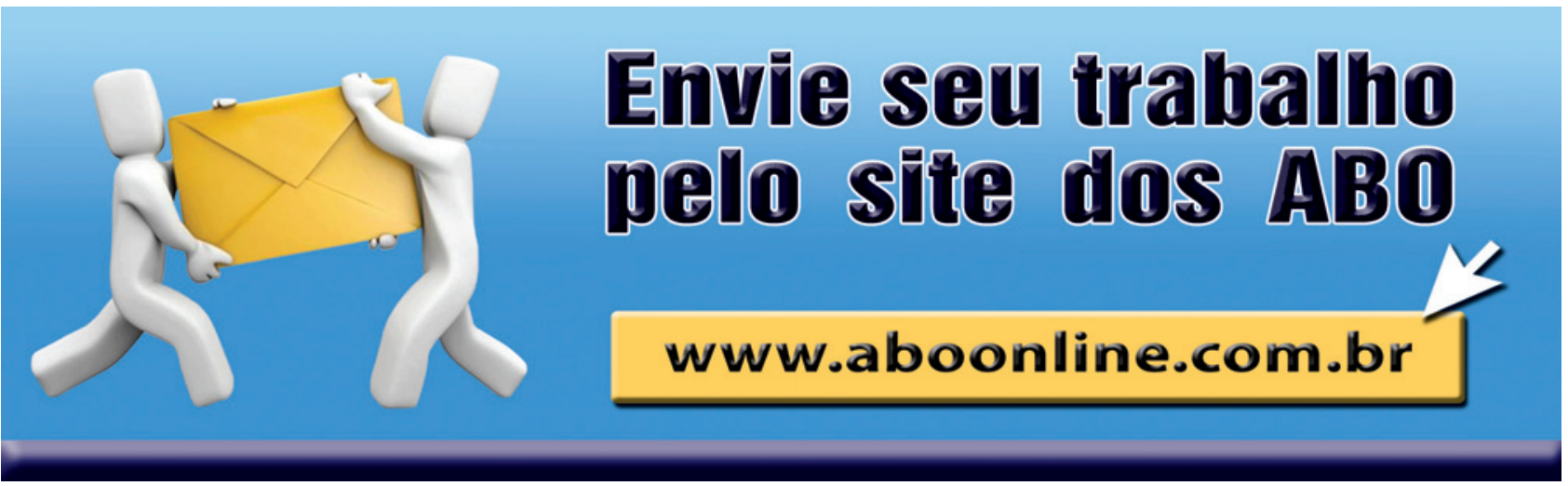

